\title{
Sarcoma of the Orbit pN0 TNM Finding v7
}

National Cancer Institute

\section{Source}

National Cancer Institute. Sarcoma of the Orbit pNO TNM Finding v7. NCI Thesaurus.

Code C88819.

Sarcoma of the orbit with no regional lymph node metastasis. (from AJCC 7th Ed.) 